\title{
Efficient, low-cost solar thermoelectric cogenerators comprising evacuated tubular solar collectors and thermoelectric modules
}

\author{
Ming Zhang a,1, Lei Miao ${ }^{\mathrm{a}, *}$, Yi Pu Kang a , Sakae Tanemura ${ }^{\mathrm{a}, \mathrm{b}, \mathrm{c}}$, Craig A.J. Fisher ${ }^{\mathrm{b}}$, \\ Gang $\mathrm{Xu}^{\mathrm{a}}$, Chun Xin $\mathrm{Li}^{\mathrm{d}}$, Guang Zhu Fan ${ }^{\mathrm{d}}$ \\ ${ }^{a}$ Key Laboratory for Renewable Energy and Gas Hydrates, Guangzhou Institute of Energy Conversion, Chinese Academy of Sciences, No. 2 Nengyuan Road, Tianhe District, \\ Guangzhou 510640, PR China \\ b Japan Fine Ceramics Center, 2-4-1 Mutsuno, Atsuta-ku, Nagoya 456-8587, Japan \\ 'Powder Technology Laboratory, Nagoya Institute of Technology, Gokiso-cho, Showa-ku, Nagoya 466-8555, Japan \\ ${ }^{\mathrm{d}}$ Dexing Solar Technology Co., Ltd., No. 1 Kesheng Road, Guangzhou Private Science Park, No. 1633 Beitai Road, Baiyun District, Guangzhou 510540, PR China
}

\section{H I G H L I G H T S}

- Successful demonstration of a pilot solar thermoelectric co-generator (STECG).

- The STECG supplies electric power and hot water simultaneously.

- Theoretical calculations fit well with the pilot STECG experimental data.

- The designed STECG is low cost and suitable for large-scale production.

\section{A R T I C L E I N F O}

\section{Article history:}

Received 3 October 2012

Received in revised form 4 March 2013

Accepted 6 March 2013

Available online 25 April 2013

\section{Keywords:}

Thermoelectric conversion

Evacuated tube heat pipe solar collector

Solar cogeneration

Electricity

Thermal energy

\begin{abstract}
A B S T R A C T
We have designed a solar thermoelectric cogenerator (STECG), which can supply electric power and heat simultaneously, by adding thermoelectric modules to the heat pipe in evacuated tubular solar collectors. A pilot experiment shows that the STECG can generate $0.19 \mathrm{~kW}$ h of electrical energy and about $300 \mathrm{l}$ of hot water at $55^{\circ} \mathrm{C}$ in 1 day when the figure of merit of the thermoelectric module, $Z T_{M}$, is 0.59 and solar insolation is less than $1000 \mathrm{~W} / \mathrm{m}^{2}$. A theoretical model for accurately predicting the thermal losses, collector efficiency and electrical efficiency of the STECG is also presented based on energy balance and heat transfer equations. For thermoelectric modules with $Z T_{M}=1$, when the solar insolation, wind velocity, ambient temperature and water temperature are $1000 \mathrm{~W} / \mathrm{m}^{2}, 1.3 \mathrm{~m} / \mathrm{s}, 25^{\circ} \mathrm{C}$ and $25^{\circ} \mathrm{C}$, respectively, the collector efficiency, output electrical power and electrical efficiency are calculated to be $47.54 \%$, $64.80 \mathrm{~W}$ and $1.59 \%$, respectively. The results show that STECGs combining heat pipes with thermoelectric modules in evacuated tubular solar water heaters are economical and practical, making them suitable for commercial production.
\end{abstract}

(c) 2013 Elsevier Ltd. All rights reserved.

\section{Introduction}

The burgeoning number of solutions proposed for reducing dependence on fossil fuels, particularly the increasing development of solar power technology, reflects intense interest in harvesting renewable energy for high-power applications. Solar energy is the largest and most widely distributed renewable energy resource on the planet, and can be utilized for a wide range of applications, such as solar water heating, photovoltaic electricity generation, solar thermal energy generation and all manner of pas-

\footnotetext{
* Corresponding author. Tel./fax: +86 2087035351.

E-mail address: miaolei@ms.giec.ac.cn (L. Miao).

1 Present address: Department of Physics, Graduate School of Engineering, Yokohama National University, Yokohama 240-8501, Japan.
}

sive and active solar architectures [1]. It thus stands to make considerable contributions to solving some of the world's acute energy problems.

Thermoelectric materials are able to convert heat to electricity directly by the movement of charge carriers across a thermal gradient (the Seebeck effect), and are thus an attractive means of generating electrical power from solar radiation. Compared to conventional electrical power generator systems, thermoelectric generators theoretically offer many advantages, such as being simple in design and having no moving parts or need for heat transfer media, making them highly reliable as well as environmentally friendly.

Devices for generating electricity using thermoelectric materials under solar radiation, otherwise known as solar thermoelectric generators (STGs or STEGs), have been a topic of research for some 
time [2-13]. Telkes [2] constructed the first STG in 1954 using a flat-plate glazed solar collector, studying its physical and electrical characteristics; a $0.6 \%$ conversion efficiency was obtained even without using a concentrator or vacuum to produce a large thermal differential. For many years only small improvements were achieved, but recently, Kraemer et al. [3] developed a flat-panel STG utilizing a high-performance nanostructured thermoelectric module (TEM) and thermal concentration solar absorbers, achieving a peak efficiency of $4.6 \%$ under solar insolation of $1000 \mathrm{~W} / \mathrm{m}^{2}$. While still low compared with the overall system efficiencies of other solar power conversion methods such as photovoltaics or solar towers, which are typically over $10 \%$, their work demonstrated that thermoelectric materials should still be considered when formulating any solar power generation strategy.

Another of the major challenges for STG technology is scalingup of the system. Traditional (fossil-fuel) thermal power plants typically produce electricity in the megawatt-hour to gigawatthour range, so to replace even a fraction of the infrastructure with STGs will require an enormous scale-up. This will only be possible if the STG is sufficiently low cost and highly efficient. STGs have the advantage over photovoltaic-based hybrid systems [14-17] in that the major components are already cheaper and mass-produced. However, if the system is scaled up, the overall heat losses become significant. Most solar thermal energy dissipates into the atmosphere and/or the surroundings through both radiation and convective heat transfer. Theoretical designs based mainly on the thermodynamics of the TEM are also associated with large errors with respect to the actual output because of the approximate nature of the calculation of solar collector efficiency. An important step in the design of efficient systems that minimize energy loss is thus the development of a reliable theoretical model for predicting the performance of various designs.

Another challenge for the practical application of STGs is lowering the cost and increasing the solar conversion efficiency of the system. The conversion efficiency of the thermoelectric module influences the overall cost and efficiency significantly. Much research is focused on developing nanostructured thermoelectrics to improve figures of merit [18-21]. However, without a major breakthrough, it is unlikely that the performance of thermoelectric materials will improve dramatically or the cost decrease significantly in the short term; a more practical approach for achieving the above aims is to generate two or three kinds of useful outputs, e.g., thermal energy, electrical power, and/or (chemical) fuel, simultaneously with the one system; that is, use cogeneration or trigeneration technology.

Thermal energy in the form of hot water is a resource that can be utilized in domestic, institutional or industrial environments. The demand for hot water increases year on year globally, leading to greater consumption of energy resources. However, the cost of evacuated tubular solar collectors in China has decreased substantially over the last decade thanks to a well-established industrial base and large market. An economical and straightforward way of improving the efficiency and reducing the costs of STEGs is thus to combine the heat pipes used in solar collectors with standard thermoelectric modules, as this enables a greater portion of the collected solar energy to be converted into useful forms. Systems using evacuated tubes are particularly attractive as they offer good energy efficiency, robustness and adaptability to a wide range of applications [22,23].

Such a system has recently been reported by He et al. [4,5]. They designed a prototype solar thermoelectric cogenerator (STECG) system that can supply either hot water or electric power, or both simultaneously, by incorporating TEGs into evacuated glass tube solar collectors. They also constructed an analytical model for their unit and predicted a maximum electrical power conversion efficiency of $3.346 \%$ for $1000 \mathrm{~W} / \mathrm{m}^{2}$ solar insolation, but this decreases to only slightly above $1 \%$ for a water temperature of $45^{\circ} \mathrm{C}$ and solar insolation greater than $600 \mathrm{~W} / \mathrm{m}^{2}$, with a thermal efficiency of about 55\% [5]. Although the electrical efficiencies are still small, the overall thermal efficiency is much greater than STGs because a good proportion of the thermal energy is captured and stored as hot water.

In a previous report [24], we presented a feasibility study for a STECG comprising a TEM and evacuated tubular collector with parabolic trough concentrator. The thermal conversion efficiency and the electrical conversion efficiency were found to reach $69 \%$ and $3.87 \%$ when the solar insolation, concentration ratio, and $Z T_{M}$ were $1000 \mathrm{~W} / \mathrm{m}^{2}, 50$, and 1 , respectively, and a forced circulation coolant was used on the cold side of the TEM.

In this paper we report the successful demonstration of a pilot solar STECG system, based on direct incorporation of thermoelectric modules within evacuated solar tubes, for supplying electric power and hot water simultaneously. In Section 2 we present details of the thermal losses, evacuated tubular solar collector efficiency and electrical efficiency of the STECG, using a thermodynamic analysis [25,26] based on an energy balance and heat transfer theory. Results from the pilot STECG experiment are presented in Section 3, and compared with the theoretical calculations. Capital costs for constructing the STECG are outlined in Section 4.

\section{System components and analysis of system efficiency}

Fig. 1 shows the structure of an evacuated tube with a TEM attached to one end. The solar selective absorber (SSA) of each evacuated tube is heated by solar insolation, delivering thermal energy to the heat pipe through the heat transfer fins. The heat pipe heats up the hot side of the thermoelectric module, and the water jacket cools the cold side, producing a temperature gradient between the two, which establishes a voltage difference resulting in an electri-

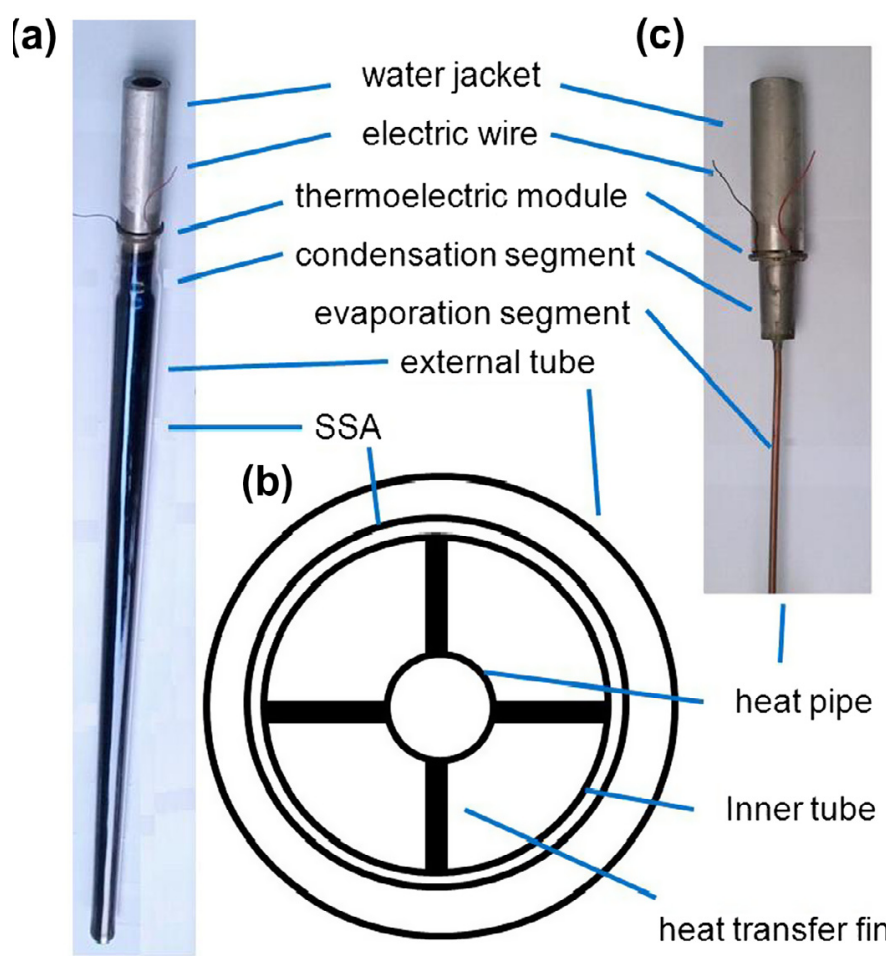

Fig. 1. The structure of an evacuated glass tube with TEM. (a) A glass tube with TEM; (b) schematic cross-section of the evacuated tube; and (c) top section of the tube with external tube, inner tube and fins removed to reveal the heat pipe. 
cal current. At the same time, the water flowing through the jacket is warmed, so that even though less than $10 \%$ of the thermal energy is converted to electricity, the remainder can be stored in the form of hot water. As demonstrated by He et al. [4,5], the solar efficiency of such a STECG can reach 50-60\%, much higher than the solar efficiency of a typical STG at less than $5 \%$.

To model a large-scale STECG we combine solar heat transfer engineering models for the solar collector with thermodynamic calculations of the TEM properties. By modeling the collector as a temperature node and equivalent thermal network, a more reliable estimate of the efficiency of the overall system under optimum conditions for the TEM and cooling components can be obtained compared to other models reported so far.

We calculated the system efficiency of our STECG by carrying out a thermodynamic analysis based on a combination of an energy balance and heat transfer equations. To estimate the heat loss and system efficiency, the following assumptions were made:

(1) The heat transfer in the system is steady state.

(2) Thermal and radiation properties of the component materials are independent of temperature.

(3) Conduction heat transfer along the long axis of the evacuated tubes is negligible.

(4) The Seebeck coefficient, electrical conductivity and thermal conductivity of the TEM are independent of temperature between $300 \mathrm{~K}$ and $500 \mathrm{~K}$.

\subsection{Optical efficiency}

The optical efficiency, $\eta_{o p t}$, which is usually defined as the ratio between the net solar energy absorbed by the SSA of an evacuated tube and the total solar incident energy impinged (solar insolation), can be rewritten as [27]

$\eta_{\text {opt }}=\tau_{e} \alpha_{T} f_{\text {ref }}$

where $\tau_{e}$ is the transmittance of the evacuated tubular glass; $\alpha_{T}$ is the solar absorbance of the SSA; and $f_{\text {ref }}$ is the multiple reflection factor between the inner and external tubes of the evacuated tube. The multiple reflection factor is given by

$f_{\text {ref }}=\frac{1}{1-\rho_{r} \rho_{e} A_{r} / A_{e}}$,

where $\rho_{r}, \rho_{e}, A_{r}$ and $A_{e}$ are the reflectance of the inner tube, the reflectance of the external tube, the area of the inner tube, and the area of the external tube, respectively. The areas are calculated from $L_{\text {tube }}, D_{r}$, and $D_{e}$, which are the length of the evacuated tube, the diameter of the inner tube, and the diameter of the external tube, respectively, and $\varepsilon_{r}$ and $\varepsilon_{e}$ are the emittance of the SSA and the external tube of the evacuated tube, respectively. All measured parameters are given in Table 1.

\subsection{Thermal losses}

Fig. 2a shows the temperature node model for a single tube used in the system thermal analysis. Some portion of the collected solar thermal energy at the SSA is dissipated into ambient and/or the sky through radiation heat transfer between the SSA and external tube, forced convection heat transfer by wind and radiation

Table 1

Geometrical and physical parameters of an evacuated tube.

\begin{tabular}{lllllllll}
\hline$\tau_{e}$ & $\alpha_{T}$ & $\rho_{r}$ & $\rho_{e}$ & $\varepsilon_{r}$ & $\varepsilon_{e}$ & $D_{r}(\mathrm{~m})$ & $D_{e}(\mathrm{~m})$ & $L_{\text {tube }}(\mathrm{m})$ \\
\hline 0.90 & 0.86 & 0.14 & 0.08 & 0.1 & 0.8 & 0.058 & 0.070 & 1.95 \\
\hline
\end{tabular}

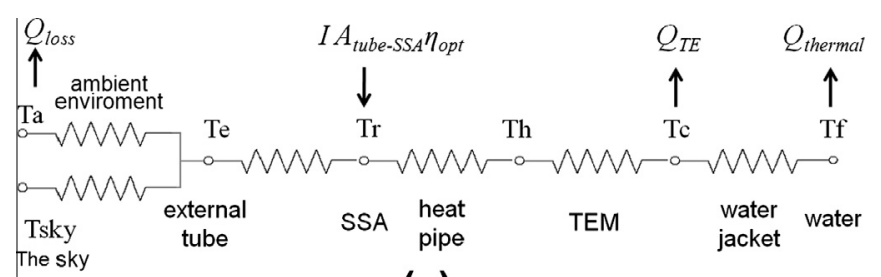

(a)

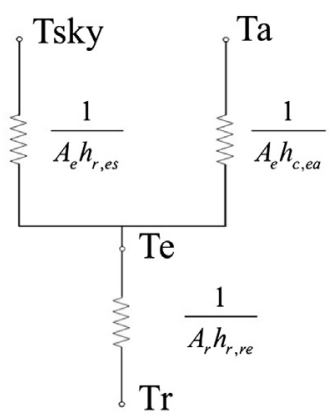

(b)

Fig. 2. (a) Single temperature node model used in the system thermal analysis, and (b) overall equivalent thermal network of an evacuated tube for thermal losses.

heat transfer between the external tube and ambient, as given in Fig. 2b.

The thermal losses from the SSA through the external tube to ambient and/or the sky can be decomposed into the following three main heat transfer mechanisms:

(1) Radiation heat transfer between the SSA and external tube: The radiation heat transfer coefficient in this case is given by [28]

$h_{r, r e}=\frac{\sigma\left(T_{e}^{2}+T_{r}^{2}\right)\left(T_{e}+T_{r}\right)}{\frac{1}{\varepsilon_{r}}+\frac{A_{r}}{A_{e}}\left(\frac{1}{\varepsilon_{e}}-1\right)}$

where $\sigma$ is the Stefan-Boltzmann constant $\left(=5.67 \times 10^{-8} \mathrm{~W} / \mathrm{m}^{2} \mathrm{~K}^{4}\right)$, and $T_{r}$ and $T_{e}$ are the temperatures of the SSA and external tube, respectively.

(2) Forced convection heat transfer: The experimentally approximated form of the forced convection heat transfer on the external tube of the evacuated glass tube by the wind is given by [28]

$h_{c, e a}=5.7+3.8 v$

where $v$ is the wind velocity in $\mathrm{m} / \mathrm{s}$.

(3) Radiation heat transfer between the external tube and the sky: Here the heat transfer coefficient is given by [28]

$h_{r, e s}=\sigma \varepsilon_{e}\left(T_{e}^{2}+T_{s k y}^{2}\right)\left(T_{e}+T_{s k y}\right)$

where $T_{\text {sky }}=0.0522 T_{a}^{1.5}$, or $T_{\text {sky }}=T_{a}-6 \mathrm{~K}$ (summer), $T_{s k y}=T_{a}-20 \mathrm{~K}$ (winter), and $T_{a}$ and $T_{s k y}$ are the temperatures of the ambient environment and the sky, respectively. The values used are listed in Table 2.

When an evacuated tube is in steady state, the temperatures of the SSA and the external tube should be constant. In this case the energy balance equation of the external tube is as follows:

Table 2

Environmental parameters used in calculating the thermal losses of a single evacuated glass tube.

\begin{tabular}{lll}
\hline$T_{a}\left({ }^{\circ} \mathrm{C}\right)$ & $T_{\text {sky }}\left({ }^{\circ} \mathrm{C}\right)$ & $v(\mathrm{~m} / \mathrm{s})$ \\
\hline 25 & 19 & 1.3 \\
\hline
\end{tabular}


$q_{e, s}^{\prime}+q_{r, r e}=q_{r, e s}+q_{c, e a}$

Here $q_{e s}^{\prime}$ is the solar power absorbed by the external tube, as given by

$q_{e, s}^{\prime}=I \alpha_{e} f_{r e f}$

where $I$ is the solar insolation, and $\alpha_{e}$ is the absorbance of the external tube $\left(\alpha_{e}=1-\tau_{e}-\rho_{e}\right)$.

The radiation heat loss between the SSA and the external tube, $q_{r, r e}$, is given by

$q_{r, r e}=h_{r, r e}\left(T_{r}-T_{e}\right)$

while the radiation heat loss between the external tube and the sky, $q_{r, e s}$, is given by

$q_{r, e s}=h_{r, e s}\left(T_{e}-T_{s k y}\right)$

and $q_{c, e a}$ is the forced convection heat loss from the external tube by the wind, given by

$q_{c, e a}=h_{c, e a}\left(T_{e}-T_{a}\right)$

The energy balance of the external tube of an evacuated tube can thus be rewritten as

$I \alpha_{e} f_{\text {ref }}+h_{r, r e}\left(T_{r}-T_{e}\right)=h_{r, e s}\left(T_{e}-T_{s k y}\right)+h_{c, e a}\left(T_{e}-T_{a}\right)$

From Eq. (10), the relationship between $T_{r}$ and $T_{e}$ can be calculated for different solar insolations. Hence from Eqs. (2)-(4), the heat loss coefficient, $U_{i}$, for different solar insolations can be obtained from [27]

$U_{t}=\frac{1}{A_{r}}\left(\frac{1}{h_{r, r e} A_{r}}+\frac{1}{\left(h_{c, e a}+h_{r, e s}\right) A_{e}}\right)^{-1}$

\subsection{Thermal resistances}

The heat transfer rate, $Q_{\text {heat }}$, of a system is defined as

$Q_{\text {heat }}=\frac{\Delta T}{R_{\text {thermal }}}$

where $\Delta T$ is the temperature difference between the heat source and the heat sink, and $R_{\text {thermal }}$ is the thermal resistance. The thermal power $Q_{t h e r m a l}$ of an evacuated tube is thus limited to

$Q_{\text {thermal }}=\frac{T_{r}-T_{a}}{R}$

where $R$ is the thermal resistance between the SSA of an evacuated tube and water, and $T_{a}$ is the ambient temperature. $Q_{\text {thermal }}$ is a useful parameter for characterizing the performance of an evacuated tube collector.

The thermal resistance between the SSA of an evacuated tube and water can be written as [29]

$R=R_{f}+R_{1}+R_{2}+R_{3}+R_{4}+R_{c 1}+R_{T E}+R_{c 2}$

where $R_{f}$ is the thermal resistance of a heat transfer fin; $R_{1}$ is the thermal resistance of the outer wall of the evaporation segment of the heat pipe; $R_{2}$ is the thermal resistance of the liquid-vapor phase change of the evaporation segment; $R_{3}$ is the thermal resistance of the vapor-liquid phase change of the condensation segment; $R_{4}$ is the thermal resistance of the outer wall of the condensation segment of the heat pipe; $R_{c 1}$ is the thermal resistance between the condensation segment of the heat pipe and the hot side of the thermoelectric module; $R_{T E}$ is the thermal resistance of the thermoelectric module; and $R_{c 2}$ is the thermal resistance between the cold side of the thermoelectric module and water.

$$
R_{1}, R_{2}, R_{3}, R_{4} \text { and } R_{c 2} \text { are given by }
$$

$R_{1}=\frac{\sigma_{m}}{\pi \lambda_{p} d_{m} l_{e}}$

$R_{2}=\frac{R T_{s} \sqrt{2 \pi R T_{s}}}{P_{v} h_{h g}^{2} \pi d_{v} l_{e}}$

$R_{3}=\frac{R T_{s} \sqrt{2 \pi R T_{s}}}{P_{v} h_{f g}^{2} \pi d_{v} l_{c}}$

$R_{4}=\frac{\sigma_{m}}{\pi \lambda_{p} d_{m} l_{c}}$

$R_{c 2}=\frac{1}{h_{c} \pi D_{0} l_{c}}$

where $\sigma_{m}=\frac{1}{2}\left(D_{0}-D_{i}\right) ; d_{m}=\frac{1}{2}\left(D_{0}+D_{i}\right) ; D_{0}$ is the outer diameter of the heat pipe; $D_{i}$ is the inner diameter of the heat pipe; $l_{c}$ is the length of the condensation segment of the heat pipe; $l_{e}$ is the length of the evaporation segment of the heat pipe; $d_{v}$ is the diameter of the steam chamber; $T_{s}$ is the temperature of the interface between the liquid in the heat pipe and the pipe wall; $h_{c}$ is the convective heat transfer coefficient between the cold side of the thermoelectric module and water; $h_{h g}$ is the latent heat of vaporization; and $R$ is the gas constant.

$R_{1}$ to $R_{4}$ are negligible compared with the overall thermal resistance. The main resistances are $R_{C 2}$ and $R_{T E}$, which affect the evacuated tube collector efficiency. Table 3 lists the values used in the calculation.

\subsection{Evacuated tube collector efficiency}

The collected solar energy at the SSA is used both for thermoelectricity generation and for heating up water, and the residual energy is eventually dissipated into ambient and/or the sky through both radiation and convection heat transfer.

The thermal power $Q_{\text {thermal }}$ received by an evacuated tube is given approximately by

$Q_{\text {thermal }}=\eta_{\text {opt }} I A_{S S A}-U_{t} A_{r}\left(T_{r}-T_{a}\right)-I_{C}^{2} R_{\text {Load }}$

where $A_{S S A}$ is the area of the SSA absorbing solar energy and $I_{C}^{2} R_{\text {Load }}$ is the output electrical power. When the thermal-to-electrical conversion is low, $I_{C}^{2} R_{\text {Load }}$ is small, and can be neglected. The evacuated tube collector efficiency, $\eta_{\text {tube }}$, is then defined as

$\eta_{\text {tube }}=\frac{Q_{\text {thermal }}}{I A_{S S A}}$

The temperature of an SSA is difficult to measure or calculate, but measuring the temperature of hot water is easy. The evacuated tube collector efficiency can thus be calculated from [28]

$\eta_{\text {tube }}=F_{f}^{\prime}\left[\eta_{o p}-\frac{U_{t}}{I}\left(T_{f}-T_{a}\right)\right]$

where $T_{f}$ is the temperature of water heated up by the evacuated tube collector, and $F_{f}$ is the evacuated tube collector efficiency factor:

$F_{f}^{\prime}=\frac{1 / U_{t}}{1 / U_{0}}=\frac{1 / \pi D_{r} L U_{t}}{1 / \pi D_{r} L U_{t}+R}$

Fig. 3 shows that the evacuated tube collector efficiency varies with the solar insolation $(I)$ and the temperature difference between the mean temperatures of the hot water $\left(T_{f}\right)$ and ambient environment $\left(T_{a}\right)$. For example, the solar collector efficiency is $47.54 \%$ when the solar insolation is $1000 \mathrm{~W} / \mathrm{m}^{2}$ and the temperature differential is $30 \mathrm{~K}$. As expected, the temperature of the SSAs 
Table 3

Thermal resistance values $(\mathrm{K} / \mathrm{W})$ used in the evaluation of the total thermal resistance of an evacuated glass tube.

\begin{tabular}{|c|c|c|c|c|c|c|c|}
\hline$R_{1}$ & $R_{2}$ & $R_{3}$ & $R_{4}$ & $R_{c 1}$ & $R_{c 2}$ & $R_{T E}$ & $R_{f}$ \\
\hline $4.16 \times 10^{-5}$ & $2.78 \times 10^{-6}$ & $5.29 \times 10^{-6}$ & $7.90 \times 10^{-4}$ & 0.02 & 0.48 & 1.24 & 0.15 \\
\hline
\end{tabular}

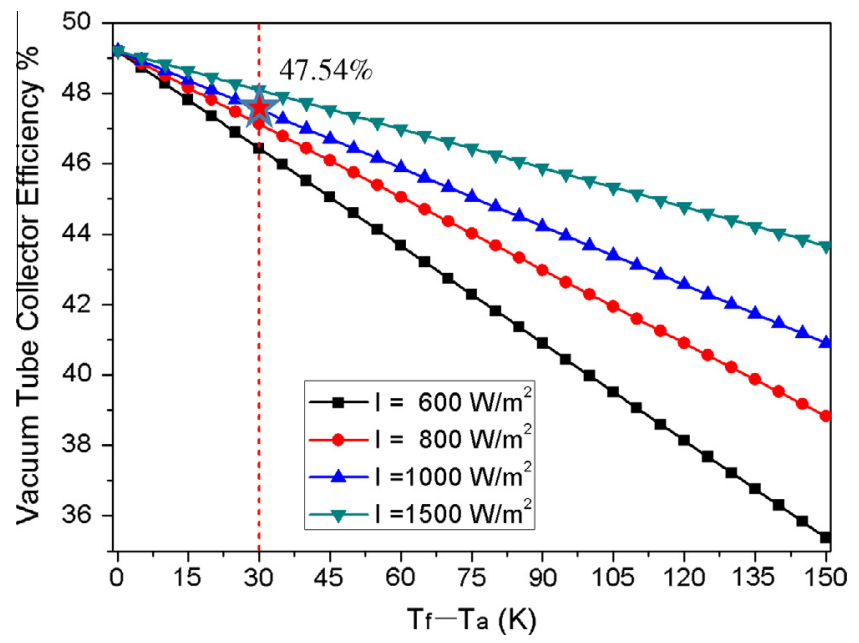

Fig. 3. Evacuated tubular collector efficiency vs. the temperature difference of the water.

increases as the solar insolation increases. Although the thermal losses to the surroundings also increase, the increase in thermal energy harvested is greater than the increase in thermal losses and the output electrical power. Consequently, the evacuated tube collector efficiency increases with the solar insolation. As the temperature of the hot water increases, however, thermal losses also increase, resulting in decreased evacuated tube collector efficiency with increasing temperature differential.

\subsection{Electrical conversion efficiency of a TEM}

The thermoelectric module consists of a p-type element and an n-type element. Whenever there is a temperature difference between the hot side and the cold side of the thermoelectric module, heat is converted directly into electricity by the movement of electronic charge carriers.

The open circuit voltage (thermal electromotive force) of a TEM comprising a p-type element and an n-type element based on the Seebeck effect can be expressed as

$E=n \int_{T_{C}}^{T_{H}}\left[S_{p}(T)-S_{n}(T)\right] d T$

where $n$ is the number of thermoelements in the TEM, $T_{H}$ is the temperature of the hot side of the TEM, $T_{C}$ is the temperature of the cold side of the TEM, and $S$ is the Seebeck coefficient. The subscripts $n$ and $p$ stand for n-type elements and p-type elements, respectively. The voltage output of a TEM is given by [3]

$$
\begin{aligned}
V= & n \int_{T_{C}}^{T_{H}}\left[S_{p}(T)-S_{n}(T)\right] d T \\
& -n I_{C}\left(\int_{T_{C}}^{T_{H}}\left[\frac{\rho_{p}}{A_{p}}\right] \frac{1}{d T_{p} / d x} d T_{p}+\int_{T_{C}}^{T_{H}}\left[\frac{\rho_{n}}{A_{n}}\right] \frac{1}{d T_{n} / d x} d T_{n}\right)
\end{aligned}
$$

where $\rho$ is the electrical resistivity, $x$ is the length of the module, and $A$ is its cross-sectional area. The current, $I_{C}$, may be expressed as
$I_{C}=\frac{n \int_{T_{C}}^{T_{H}}\left[S_{p}(T)-S_{n}(T)\right] d T}{n\left(\int_{T_{C}}^{T_{H}}\left[\frac{\rho_{p}}{A_{p}}\right] \frac{1}{d T_{p} / d x} d T_{p}+\int_{T_{C}}^{T_{H}}\left[\frac{\rho_{n}}{A_{n}}\right] \frac{1}{d T_{n} / d x} d T_{n}\right)+R_{\text {Load }}}$

where $R_{\text {Load }}$ is the load resistance, and

$R_{e}=n\left(\int_{T_{C}}^{T_{H}}\left[\frac{\rho_{p}}{A_{p}}\right] \frac{1}{d T_{p} / d x} d T_{p}+\int_{T_{C}}^{T_{H}}\left[\frac{\rho_{n}}{A_{n}}\right] \frac{1}{d T_{n} / d x} d T_{n}\right)$

is the inner resistance of the TEM. The power output can be calculated from $P_{T E}=V I_{C}$.

It is well known that the Seebeck coefficient, electrical conductivity and thermal conductivity depend on temperature. However, thermoelectric properties can be assumed to be independent of temperature with an acceptable degree of accuracy for reasonably narrow temperature ranges.

Fig. 4 shows the measured values of open circuit voltage, short circuit current and output electrical power of the TEM as a function of the temperature difference across the TEM relative to a cold side temperature of $30^{\circ} \mathrm{C}$. The hot side of the TEM was heated by an electric heater, and the cold side cooled by water. The temperature of the hot and cold sides of the TEM were controlled by changing the power provided by the electric heater and the temperature of the cooling water. The temperatures of the hot and cold sides of the TEM were measured using a resistance thermometer (PT100) based on the relationship between electrical resistance and temperature of the resistance thermometer. The measuring accuracy was $\pm 41-46 \mathrm{mK}$. With increasing temperature difference, the thermal electromotive force increases, leading to an increase in all three values.

Unfortunately, it was difficult to measure the Seebeck coefficient, electrical conductivity, thermal conductivity, and temperatures of the cold and hot sides of the TEMs in the pilot experiment. The electrical efficiency of the STECG was therefore calculated based on the energy balance and heat transfer equations presented in Section 2.6.

\subsection{Electrical efficiency of the STECG}

The heat used by the TEM to generate electricity, $Q_{T E}$, can be separated into contributions from the Peltier heat, thermal conductance and Joule heat [30], giving

$Q_{T E}=S I_{C} T_{H}+K\left(T_{H}-T_{C}\right)-\frac{1}{2} I_{C}^{2} R_{e}$

It is difficult to obtain $Q_{T E}$ from Eq. (28), because the relationships between Peltier heat, thermal conductance and Joule heat are complex in a TEM. $Q_{T E}$, however, is supplied by the solar energy absorbed on the SSA, so that $Q_{T E}$ can be obtained from

$Q_{T E}=\eta_{o p t} I A_{S S A}-U_{t} A_{r}\left(T_{r}-T_{a}\right)$

The thermal-to-electrical conversion efficiency of a TEM can be expressed as [30]

$\eta_{T E}=\frac{\left(T_{H}-T_{C}\right)\left(\sqrt{1+Z T_{M}}-1\right)}{T_{H}\left(\sqrt{1+Z T_{M}}+T_{C} / T_{H}\right)}$

where $T_{M}$ is the mean temperature of the hot and cold sides of the TEM, i.e., $T_{M}=\left(T_{H}+T_{C}\right) / 2$; and $Z T_{M}$ is the figure of merit, which depends on the thermoelectric parameters (Seebeck coefficient, thermal conductivity, and electrical conductivity). From Eq. (12), the 


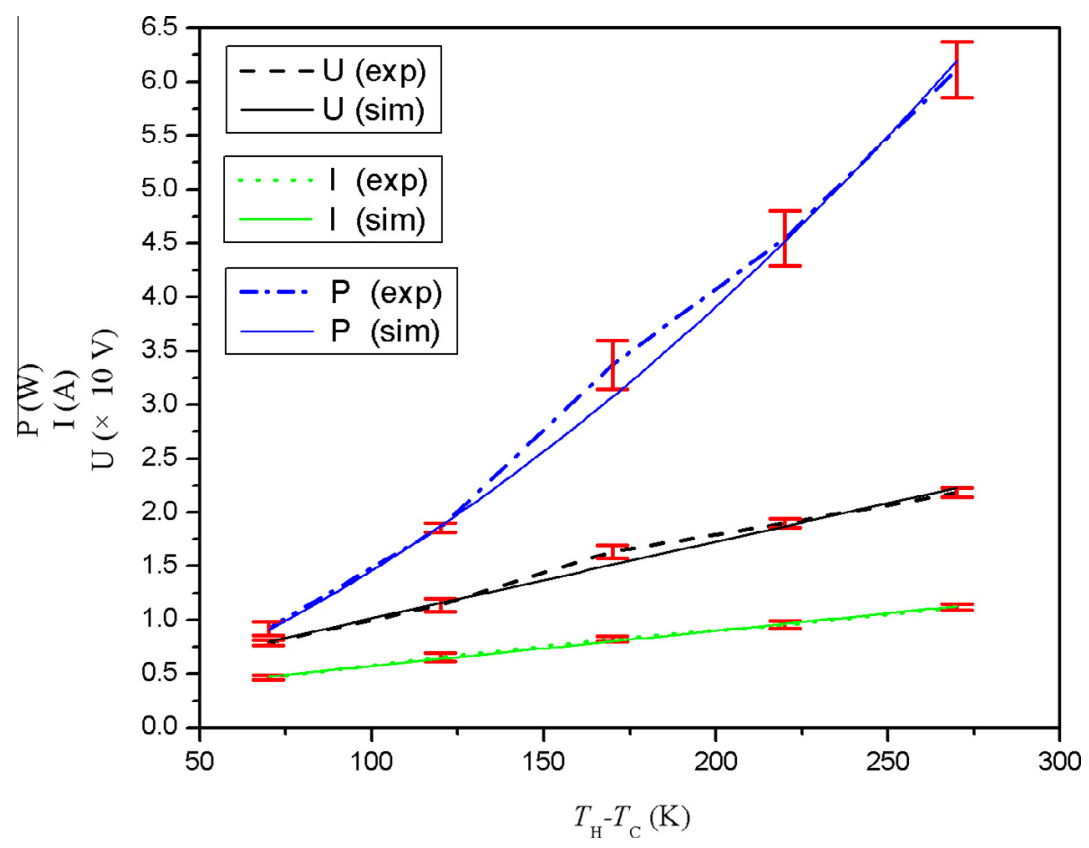

Fig. 4. Open circuit voltage, short circuit current, and output electrical power as functions of the temperature difference across the TEM.

temperature difference is directly proportional to the heat transfer rate and thermal resistance:

$T_{C}=T_{a}+Q_{T E} R_{C 2}$

or $\quad T_{C}=T_{r}-Q_{T E}\left(R_{f}+R_{1}+R_{2}+R_{3}+R_{4}+R_{C 1}\right)$

$T_{H}=T_{a}+Q_{T E}\left(R_{C 2}+R_{T E}\right)$

or $\quad T_{H}=T_{r}-Q_{T E}\left(R_{f}+R_{1}+R_{2}+R_{3}+R_{4}+R_{c 1}+R_{T E}\right)$

The output electrical power of the evacuated tubular solar collector is

$P_{T E}=Q_{T E} \eta_{T E}$

The electrical efficiency of the STECG may be defined as the ratio of the electrical power output to the received solar insolation, i.e.,

$\eta_{\text {ele }}=\frac{Q_{T E} \eta_{T E}}{I A_{S S A}}$

The temperature is directly influenced by the solar insolation. From Fig. 5a it can be seen that both $T_{H}$ and $T_{C}$ increase with increasing solar insolation, but the increase in $T_{H}$ is larger than that of $T_{C}$, so that the temperature difference between $T_{H}$ and $T_{C}$ also increases. Although the thermal losses to the surroundings and atmosphere also increase, the rate of increase in electrical power output is larger than the rate of increase in thermal losses. Therefore increased solar insolation promotes greater electrical power output and electrical efficiency.

Fig. 5b shows that the value of $Z T_{M}$ has a large impact on output electrical power and electrical efficiency as well. The larger value of $Z T_{M}$ leads to a significant increase in output electrical power and electrical efficiency. Thus increasing both solar insolation and the value of $Z T_{M}$ can produce significant improvements in the thermal-to-electrical efficiency of the STECG system.

According to this model, when the solar insolation, wind velocity, ambient temperature and temperature of water are $1000 \mathrm{~W} /$ $\mathrm{m}^{2}, 1.3 \mathrm{~m} / \mathrm{s}, 25^{\circ} \mathrm{C}$ and $25^{\circ} \mathrm{C}$, respectively, the calculated results show that the output electrical power and electrical efficiency are $1.22 \mathrm{~W}$ and $1.08 \%$, respectively, when $Z T_{M}=0.59$; and $1.80 \mathrm{~W}$ and $1.59 \%$, respectively, when $Z T_{M}=1$.

\section{Pilot experiment: results and discussion}

The pilot STECG system (Fig. 6) comprises 36 solar evacuated tubes ( $70 \mathrm{~mm} \times 2100 \mathrm{~mm}$ ) and $36 \mathrm{Bi}_{2} \mathrm{Te}_{3}$ TEMs (TEC1-127; Suzhou ICY Cooler Electronic Co., Ltd.) with a thermal resistance of $1.24 \mathrm{~K} /$ $\mathrm{W}$ per TEM and a module $Z T_{M}$ of about 0.59 . The size of the TEM is $40 \mathrm{~mm} \times 40 \mathrm{~mm} \times 4.0 \mathrm{~mm}$ and composed by the matrix of 127 thermoelements which had a length of $1.5 \mathrm{~mm}$. Each solar evacuated tube contains one heat pipe and one TEM. The electrical power generated by the pilot STECG system as a function of time over a 1-day period is shown in Fig. 7. From Fig. 5b, as the solar insolation increases, the temperature across the TEM can also be seen to increase. A larger temperature difference across the TEM, which is proportional to the heat transfer rate, improves the thermal electromotive force generated by the Seebeck effect and increases the electrical efficiency, so that the electric power of the STECG increased sharply with increasing solar insolation between the hours of 9:00 AM and 12:00 noon, reaching a peak around noon. When the solar insolation, wind velocity, ambient temperature and temperature of water were $958 \mathrm{~W} / \mathrm{m}^{2}, 1.3 \mathrm{~m} / \mathrm{s}$, $25^{\circ} \mathrm{C}$ and $25^{\circ} \mathrm{C}$, respectively, the output electrical power reached $41.3 \mathrm{~W}$, with a system electrical efficiency of $1.06 \%$. The output of generated electricity during the experiment reached $0.19 \mathrm{~kW} \mathrm{~h}$.

At the same time as generating electrical energy, the STECG also successfully heated up water as it passed through the heat pipes. About 3001 of water was warmed from $25^{\circ} \mathrm{C}$ to $55^{\circ} \mathrm{C}$ by the STECG. The daily solar exposure was $1.987 \times 10^{7} \mathrm{~J} / \mathrm{m}^{2}$, and the area of the collector for absorbing solar energy is $A=D_{r} \times L_{\text {tube }}$ $\times 36=4.07 \mathrm{~m}^{2}$, giving an average evacuated tube collector efficiency of $46.72 \%$ according to Eq. (21). The measured electrical efficiency and evacuated tube collector efficiency match with the calculated results $(1.03 \%$ and $47.54 \%$ ) very well, and are comparable to the results of $\mathrm{He}$ et al. [5]. The success of the pilot experiment and its simple design demonstrates that scaling up of these cogenerator systems is eminently feasible.

\section{Improving the efficiency of the STECG}

A solar thermoelectric cogenerator (STECG) can supply electric power and hot water simultaneously. The system efficiency is thus 

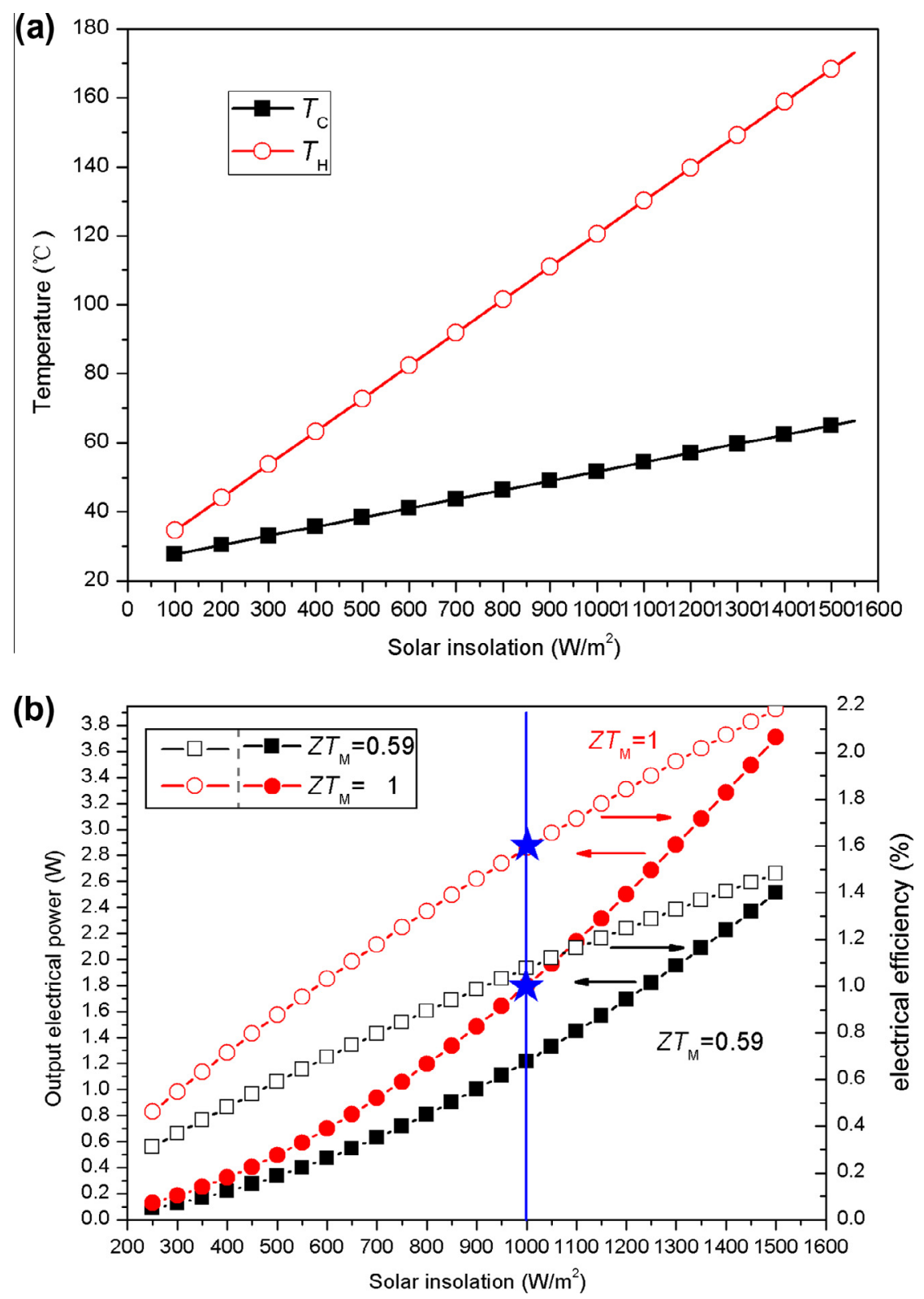

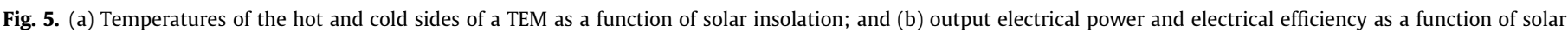
insolation.

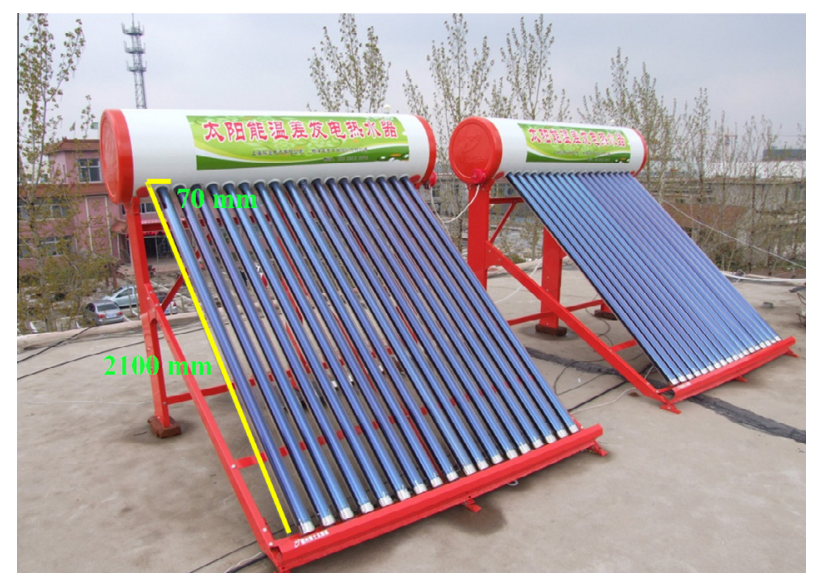

Fig. 6. The pilot STECG co-generator comprised of two evacuated tubular solar collectors, each with 18 tubes. Each tube contains a thermoelectric module. composed of two main parts: the electrical efficiency and the evacuated tube collector efficiency.

The value of $Z T_{M}$ of the thermoelectric module is the most important parameter for improving the conversion efficiency of solar energy to electricity, as shown in Fig. 5b. The commercially available TEMs used in our pilot experiment have a low figure of merit of $Z T_{M}=0.59$ (compared to the best conventional materials which have $Z T_{M}=0.89$ ) so that for a typical solar insolation on a sunny day in the northern hemisphere of $1000 \mathrm{~W} / \mathrm{m}^{2}$, the electrical efficiency is $1.08 \%$; this can be increased by $50 \%$ when $Z T_{M}=1$, giving an electrical efficiency of $1.59 \%$. Such materials have been prepared at the laboratory level, but are still expensive and require further research [33]. Materials with $Z T_{M}=2$ would provide an even higher electrical efficiency of $2.46 \%$. Intense research is being carried out into developing thermoelectric materials with high figures of merit, with the use of nanostructured or low-dimensional oxides, semiconductors, and even organic-based materials being the focus of much attention [34]. Over the next 5-10 years, some 


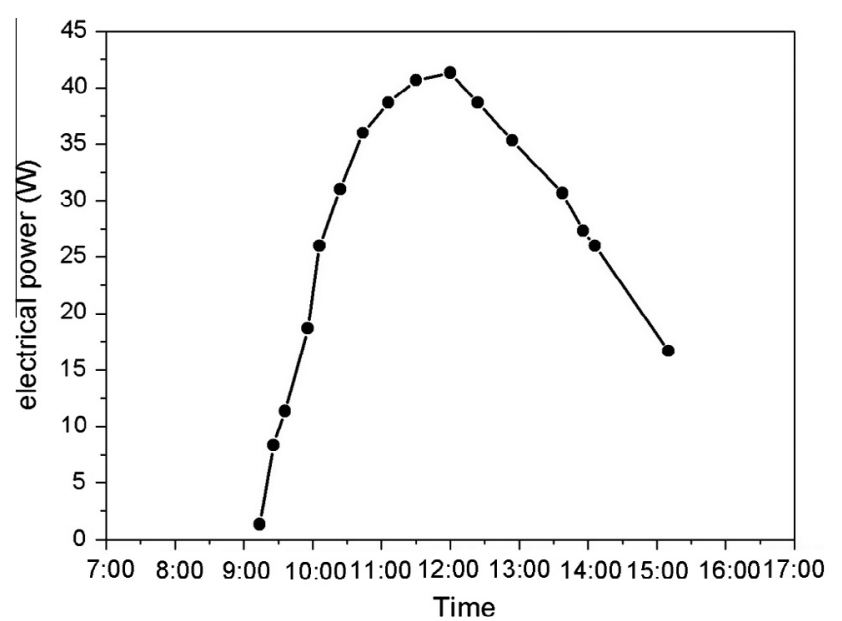

Fig. 7. The output power from the STECG pilot system operated for 1 day as a function of time.

of these materials will no doubt find their way onto the market, making STECGs an even more attractive alternative to the heavily polluting and carbon-intensive technologies that most industries and households currently rely upon to meet their energy needs.

The second most important parameter for improving the conversion efficiency is the solar insolation. When the solar insolation increases from 1000 to $1500 \mathrm{~W} / \mathrm{m}^{2}$, electrical efficiency increases to $2.2 \%$ under $Z T_{M}=1$ as shown in Fig. $5 \mathrm{~b}$. If $Z T_{M}=2$, the electrical efficiency will be $3.37 \%$. Simultaneously, as seen in Fig. 3, evacuated tube collector efficiency increases modestly with increasing solar insolation as well, from $47.54 \%$ under $1000 \mathrm{~W} / \mathrm{m}^{2}$ to $48.09 \%$ under $1500 \mathrm{~W} / \mathrm{m}^{2}$. This means the thermoelectric co-generator should be sited in a position most favorable for catching the sun's rays, and will be most effective in locales with long periods of fine weather. Another important aspect of STECG design is to optimize insolation, and this may be achieved, for example, by introducing automatic sun-tracking functionality or use of solar-concentration devices. These promising aspects are topics for future research.

The third most important parameter for improving the conversion efficiency is the thermal resistance of the system. According to Eqs. (31a)-(32b), as the thermal resistance of the TEM increases and $R_{1} \sim R_{f}$ decreases, the temperature difference between the hot and cold sides of the TEM increases, which increases the output electrical power. At the same time, a decrease in the thermal resistance $R_{1} \sim R_{f}$ increases the evacuated tube collector efficiency. Finally, improvements in the optical efficiency of the glass tubes through materials design and engineering will not only optimize solar ray concentration, but also produce a high overall electrical efficiency over the lifetime of the apparatus.

Assuming that such targets can be achieved, namely $Z T_{M}=2$ under a solar insolation of $1500 \mathrm{~W} / \mathrm{m}^{2}$, the combined electrical efficiency of $3.37 \%$ and evacuated tube collector efficiency of $48.09 \%$ will provide a total system efficiency of $51.46 \%$. This value is higher than any solar TEG system reported to date.

\section{Capital costs of the pilot STECG}

There is already a huge market for evacuated tubular solar collectors in China. They currently account for more than $80 \%$ of solar water heating in China because of their high efficiency and nonsusceptibility to freezing [35]. By 2006, the annual production of solar collectors had exceeded 20 million $\mathrm{m}^{2}$ and the total installation area had reached 90 million $\mathrm{m}^{2}$ [35]. As a consequence of this mass production, evacuated tubular solar collectors and the evacuated tube heat pipes used in their production are inexpensive, widely available and of good quality.

The size of the STECG tested in the pilot experiment is initially envisaged for use by a single household to generate electricity for direct domestic consumption and provide hot water for showering, washing, cooking, etc. However, with improvements in efficiency and scaling up of these systems, feeding of excess electricity generated into the main grid is another scenario with a high probability of being realized in the future, and may be an economical means for the owner to recover the capital costs in a shorter time if this electricity can be sold at competitive rates. It may also provide a useful means of load balancing if sufficiently large numbers of households have STECGs installed.

The costs of the various components used in the pilot STECG examined in this study are listed in Table 4. The total cost of a STECG comprising 36 evacuated tubes (with heat pipes) and 36 TEMs for bonding to the heat-pipe terminations is about US\$2380.86, making it affordable for most middle-income households. Our pilot experiment showed that the STECG can generate $0.19 \mathrm{kWh}$ of electrical energy and about $300 \mathrm{l}$ of hot water at $55^{\circ} \mathrm{C}$ in 1 day under typical conditions. Based on our results, assuming 220 days of sunlight per year, $2552 \mathrm{~kW}$ h of energy is saved per year. The average retail price of residential electricity was 11.76 cents/kW h as of March 2012 in the United States. These figures thus suggest a return on investment in about 8 years $[31,32]$. With the aid of subsidies and assuming an increase in cost of more conventional energy sources (i.e., fossil fuels), this time period may be significantly shortened.

Our estimated costs can be compared with typical costs of residential solar water heating systems, which were about US\$6000 in the United States (decreasing in many places to US $\$ 2500$ once subsidies and tax rebates are taken into account) in 2010 for a $2800 \mathrm{~kW}$ system [36], and about US\$4800 in the United Kingdom [37], providing savings of about $200 \mathrm{~kW} \mathrm{h/month.} \mathrm{Solar} \mathrm{cell} \mathrm{prices,}$ on the other hand, currently vary somewhere between US\$0.79 and US\$2.44 per watt depending on the location, manufacturer, and country [38]. In comparison, our pilot STECG system could provide a saving of about $212.7 \mathrm{~kW} \mathrm{~h} /$ month ( $2552 \mathrm{~kW} \mathrm{~h}$ per year) even without further optimization. The total cost of the STECG used in our pilot experiment is significantly lower than systems sold in the USA or UK, but even if one assumes higher installation costs, etc., in these countries, they are clearly competitive with other solar energy units currently on the market. Finally although prices of photovoltaic systems are declining rapidly year on year [39], similar economies of scale are expected to apply to STECG systems, and any subsidies or other financial incentives will make them even more attractive to consumers.

According to the manufacturer specifications, the evacuated tubes and TEMs both have lifetimes of around 20 years, so the STECG can be expected to have a comparable lifetime. Our pilot study demonstrated that not only are STECGS easy to manufacture, but they are also economical and simple to implement. Long term studies are now under way to demonstrate the robustness and practicality of our solar thermoelectric co-generators under typical real-world conditions; the results presented here serve as a proofof-concept, and suggest that there are no serious hurdles to overcome before they can be implemented on a wide scale.

Table 4

Breakdown of the cost of the pilot STECG.

\begin{tabular}{lclc}
\hline Module & Unit price (US\$) & Number & Cost (US\$) \\
\hline Evacuated tube & 23.81 & 36 & 857.16 \\
TEM & 15.87 & 36 & 571.32 \\
Battery, water tank, etc. & 952.38 & 1 & 952.38 \\
& & Total & 2380.86 \\
\hline
\end{tabular}




\section{Conclusions}

We have presented results from a pilot experiment of a lowcost solar thermoelectric co-generator (STECG) based on evacuated tubular solar collectors incorporating thermoelectric modules (TEMs), which can supply both electricity and heat simultaneously. Our pilot experiment demonstrates that STECGs are economical and practical, and should be suitable for real-world application. Further breakthroughs in materials R\&D will only accelerate this process.

The thermal losses, evacuated tube collector efficiency and electrical efficiency of the STECG were analyzed using a thermodynamic model based on an energy balance and heat transfer concepts. The accuracy and reliability of the model makes it helpful for predicting the performance of the STECG under a range of environmental conditions, and can also be used for designing and improving STECGs.

The pilot experiment generated $0.19 \mathrm{~kW}$ h of electrical power and about 3001 of hot water at $55^{\circ} \mathrm{C}$ in 1 day when $Z T_{M}=0.59$ and solar insolation was less than $1000 \mathrm{~W} / \mathrm{m}^{2}$. When $Z T_{M}=1$ and solar insolation is $1000 \mathrm{~W} / \mathrm{m}^{2}$, the efficiency of evacuated tubular solar collector, output electrical power and electrical efficiency were predicted to be $47.54 \%, 64.80 \mathrm{~W}$ and $1.59 \%$, respectively, even when the evacuated tube collector efficiency and $Z T_{M}$ value for the TEM are low.

STECGs made from evacuated tubular solar collectors with integrated TEMs are easy to fabricate and only slightly more expensive than solar collectors on their own. The total cost of our STECG, which consisted of 36 heat pipes in 36 evacuated tubes with 36 TEMs, was about US\$2380.86. The return on investment of the STECG is estimated to be about 8 years. The STECGs can supply electric energy and hot water simultaneously, will have a wide field of application and require little maintenance, making them ideal for providing power to regions where there is as yet no electricity network. Our pilot study shows that these low cost alternatives to PV or PV-hybrid solar power systems are an attractive solution to the problem of increasing energy demand and $\mathrm{CO}_{2}$ emissions that, after further field testing, should be comparatively easy to implement.

\section{Acknowledgements}

This work was supported by the National Nature Science Foundation of China 51172234, and Guangdong Provincial Science and Technology Grant 2011B010100043 and Chinese Academy of Sciences: Key Laboratory of Renewable Energy and Natural Gas Hydrate Foundation, Grant No. y107j3.

\section{References}

[1] Tian Y, Zhao CY. A review of solar collectors and thermal energy storage in solar thermal applications. Appl Energy 2013;104:538-53.

[2] Telkes M. Solar thermoelectric generators. J Appl Phys 1954;25:765-77.

[3] Kraemer D, Poudel B, Feng H-P, Caylor JC, Yu B, Yan X, et al. High-performance flat-panel solar thermoelectric generators with high thermal concentration. Nat Mater 2011;10:532-8.

[4] He W, Su YH, Riffat SB, Hou JX, Ji J. Parametrical analysis of the design and performance of a solar heat pipe thermoelectric generator unit. Appl Energy 2011;88:5083-9.

[5] He W, Su YH, Wang YQ Riffat SB, Ji J. A study on incorporation of thermoelectric modules with evacuated-tube heat-pipe solar collectors. Renew Energy 2012;37:142-9.

[6] Omer SA, Infield DG. Design optimization of thermoelectric devices for solar power generation. Sol Energy Mater Sol Cells 1998;53:67-82.

[7] Omer SA, Infield DG. Design and thermal analysis of a two stage solar concentrator for combined heat and thermoelectric power generation. Energy Convers Manage 2000;41:737-56.
[8] Atik K. Numerical simulation of a solar thermoelectric generator. Energy Source Part A 2011;33:760-7.

[9] Eswarmoothy M, Shanmuam S. A numerical model to compute heat loss in the focal receiver of a solar parabolic dish thermoelectric generator. Energy Source Part A 2012;34:959-65.

[10] Xiao JS, Yang TQ, Li P, Zhai PC, Zhang QJ. Thermal design and management for performance optimization of solar thermoelectric generator. Appl Energy 2012;93:33-8.

[11] Chen G. Theoretical efficiency of solar thermoelectric energy generators. J Appl Phys 2011;109:104908-1-8-8.

[12] McEnaney K, Kraemer D, Ren ZF, Chen G. Modeling of concentrating solar thermoelectric generator. J Appl Phys 2011;110:074502-1-2-6.

[13] Kraemer D, McEnaney K, Chiesa M, Chen G. Modeling of and optimization of solar thermoelectric generators for terrestrial applications. Sol Energy 2012;86:1338-50.

[14] Van Sark WGJHV. Feasibility of photovoltaic-thermoelectric hybrid modules. Appl Energy 2012;88:2785-90.

[15] Wang N, Han L, He HC, Park NH, Koumoto K. A novel high-performance photovoltaic-thermoelectric hybrid devices. Energy Environ Sci 2011;4:3676-9.

[16] Rockendorf G, Sillmann R, Podlowski L, Litzenburger B. PV-hybrid and thermoelectric collectors. Sol Energy 1999;67:227-37.

[17] Chavez-Urbiola EA, Vorobiev YV, Bulat LP. Solar hybrid systems with thermoelectric generators. Sol Energy 2012;86:369-78.

[18] Dresselhaus MS, Chen G, Tang MY, Yang R, Lee H, Wang D, et al. New directions for low-dimensional thermoelectric materials. Adv Mater 2007;19:1043-53.

[19] Liu WS, Yan X, Chen G, Ren ZF. Recent advancement in thermoelectric nanocomposites. Nano Energy 2012;1:42-56.

[20] Mehta RJ, Zhang YL, Karthik C, Singh B, Siegel RW, Borca-Tasciuc T, et al. A new class of doped nanobulk high-figure-of merit thermoelectrics by scalable bottom-up assembly. Nat Mater 2012;11:233-40.

[21] Son JS, Choi MK, Han MK, Park KS, Kim JY, Lim SJ, et al. n-Type nanostructured thermoelectric materials prepared from chemically synthesized ultrathin $\mathrm{Bi}_{2} \mathrm{Te}_{3}$ nanoplates. Nano Lett 2012;12:640-7.

[22] Szokolay SV. Introduction to architectural science: the basis of sustainable design. Oxford: Architectural Press; 2005. p. 86-94.

[23] Kim JT, Ahn HT, Han H, Kim HT, Chun W. The performance simulation of allglass vacuum tubes with coaxial fluid conduit. Int Commun Heat Mass Transfer 2007;34:587-97.

[24] Miao L, Zhang M, Tanemura S, Tanaka T, Kang YP, Xu G. Feasibility study on the use of a solar thermoelectric cogenerator comprising a thermoelectric module and evacuated tubular collector with parabolic trough concentrator. J Electron Mater 2012;41:1759-65.

[25] Chen JC. Thermodynamic analysis of a solar-driven thermoelectric generator. J Appl Phys 1996;79:2717-22.

[26] Amatya R, Ram RJ. Solar thermoelectric generator for micropower applications. J Electron Mater 2010;39:1735-40.

[27] Oommen R, Jayaraman S. Development and performance analysis of compound parabolic solar concentrators with reduced gap losses - oversized reflector. Energy Convers Manage 2001;42:1379-99.

[28] Duffie JA, Beckman WA. Solar energy thermal processes, chapter 7: flat plate collectors, chapter 8: focusing collectors. New York (NY): Wiley; 1974. p. 120214.

[29] Ernst DM. Evaluation of theoretical heat pipe performance. In: Record IEEE thermionic conversion specialist conference, Pala Alto, CA, USA; 1967. p. 34954.

[30] Rowe DM. Thermoelectrics handbook: nano to macro. In: Rowe DM, editor. Gereral principles and basic considerations. New York: CRC Taylor \& Francis; 2006 [chapter 1.3].

[31] Kalogirou SA. Solar thermal collectors and applications. Prog Energy Combust Sci 2004;30:231-95.

[32] Kalogirou S. Economic analysis of solar energy systems using spreadsheets. In: Proceedings of the world renewable energy congress IV, Denver, Colorado, USA, vol. 2; 1996. p. 1303-7.

[33] Yan X, Poudel B, Ma Y, Liu WS, Joshi G, Wang H, et al. Experimental studies on anisotropic thermoelectric properties and structures of n-type $\mathrm{Bi}_{2} \mathrm{Te}_{2.7} \mathrm{Se}_{0.3}$. Nano Lett 2010;10:3373-8.

[34] Yang J, Yip H-L, Jen AK-Y. Rational design of advanced thermoelectric materials. Adv Energy Mater 2013. http://dx.doi.org/10.1002/ aenm.201200514.

[35] Wang RZ, Zhai XQ. Development of solar thermal technologies in China. Energy 2010;35:4407-16.

[36] SRP EarthWise solar energy for your home. <http://srpnet.com/> [accessed 21.02.13].

[37] Solar water heating systems explained - benefits, costs, savings, earnings, suitability. <http://energysavingtrust.org.uk/> [accessed 20.02.13].

[38] Ecobusiness links free solar panel survey. <http://www.ecobusinesslinks.com/ surveys/free-solar-panel-price-survey/> [accessed 20.02.13]

[39] Barbose G, Darghouth N, Wiser R, Seel J. Tracking the Sun IV: an historical summary of the installed cost of photovoltaics in the United States from 1998 to 2010. Lawrence Berkeley National Laboratory report; September 2011. 